\title{
Corrigendum: Using Underwater Pulse Oximetry in Freediving to Extreme Depths to Study Risk of Hypoxic Blackout and Diving Response Phases
}

\author{
Eric Mulder $^{1 *}$, Arne Sieber ${ }^{1}$ and Erika Schagatay ${ }^{1,2}$ \\ ${ }^{1}$ Environmental Physiology Group, Department of Health Sciences, Mid Sweden University, Östersund, Sweden, ${ }^{2}$ Swedish \\ Winter Sports Research Centre, Mid Sweden University, Östersund, Sweden
}

Keywords: breath-hold diving, apnea, arterial oxygen saturation, syncope, heart rate, bradycardia, exercise, oxygen conservation

\section{A Corrigendum on}

OPEN ACCESS

Approved by:

Frontiers Editorial Office,

Frontiers Media SA, Switzerland

*Correspondence:

Eric Mulder

eric.mulder@miun.se

Specialty section:

This article was submitted to

Environmental, Aviation and Space

Physiology,

a section of the journal

Frontiers in Physiology

Received: 26 April 2021

Accepted: 24 June 2021

Published: 19 July 2021

Citation:

Mulder E, Sieber A and Schagatay E

(2021) Corrigendum: Using Underwater Pulse Oximetry in

Freediving to Extreme Depths to Study Risk of Hypoxic Blackout and

Diving Response Phases.

Front. Physiol. 12:700804.

doi: 10.3389/fphys.2021.700804
Using Underwater Pulse Oximetry in Freediving to Extreme Depths to Study Risk of Hypoxic Blackout and Diving Response Phases

by Mulder, E., Sieber, A., and Schagatay, E. (2021). Front. Physiol. 12:651128. doi: $10.3389 /$ fphys.2021.651128

In the original article, we neglected to include the author, Arne Sieber. The corrected Author Contributions Statement appears below.

"EM contributed to the study design, planning and organization of field study tests and procedures, data collection, data analysis, and the manuscript writing. AS contributed with the original idea to build an underwater pulse oximeter, to construction and use of the underwater pulse oximeter, to data interpretation and analysis, and revising the manuscript. ES contributed with the original idea, planning and organization of field study tests and procedures, data analysis, and the manuscript writing. All authors contributed to the article and approved the submitted version."

In the original article, the Funding Statement was incomplete. The new, correct Funding should be: "Funding was obtained through a donation from the Francis family in memory of their son/brother, who drowned from hypoxic blackout while snorkeling and holding his breath to dive underwater, and by a grant from the Swedish Research Council for Sport Science (CIF).”

The authors apologize for this error and state that this does not change the scientific conclusions of the article in any way. The original article has been updated.

Copyright $\odot 2021$ Mulder, Sieber and Schagatay. This is an open-access article distributed under the terms of the Creative Commons Attribution License (CC BY). The use, distribution or reproduction in other forums is permitted, provided the original author(s) and the copyright owner(s) are credited and that the original publication in this journal is cited, in accordance with accepted academic practice. No use, distribution or reproduction is permitted which does not comply with these terms. 